\title{
The "ANTHROPOCENE": What is its geological utility? (Answer: It has none!)
}

\author{
George Devries Klein \\ Geologist, Author, and Professor Emeritus, Geology, University of Illinois @Urbana-Champaign P.O. Box 24114 \\ Barrigada, GU, 96921-4114, USA.Email: gdkgeo@earthlink.net
}

(Received February 2, 2015: Revised accepted June 20, 2015)

Since proposed in 2000, the concept of the "Anthropocene" has filtered through the geological literature (See Zalasiewicz, et al, In Press, for a brief summary review). Inevitably, it attracted the attention of the IUGS which formed a Working Group of the International Commission on Stratigraphy (ICS) to examine it. Although the base of the "Anthropocene" is diachronous (Edgeworth et al, 2015), the chair of the ICS Working Group on the Anthropocene has proposed that the "Anthropocene's" base should be defined now by the isotopic signature of the world's first nuclear explosion on July 16, 1945, at Alamogorda, NM, (Zalasiewicz,et al, In Press). Other work (Corcoran et al, 2014) shows that plastic garbage makes an anthropogenic global marker as well.

The real question is, does the "Anthropocene" even have utility? Granted, human reworking is observable at the surface or near surface, but is it geologically regional in scale? How would one map the proposed isotopic marker in the field? Will it mean repeated trips to the field to collect samples, analyze them isotopically in the laboratory, and then go back to the field to place the boundary thus increasing a field geologist's carbon footprint? Or will geologists now be required to carry a Geiger counter or portable Gamma Ray tool to be sure not to miss the critical basal boundary? (I see a business opportunity here to develop miniaturized versions for field use).

Where will the type section be? Alamogorda, NM, where the original atomic bomb test took place, is a military restricted area requiring extensive security clearances to even visit, much less do field work, if it will even be allowed. Obviously, a search for a standard section will be required, but where will it be and who decides? How long will it take and how many international field excursions will be required before the ICS makes such a decision?

Has the isotopic signature representing the base of the "Anthropocene" ever been identified and correlated in deep sea piston cores recovered by oceanographic institutions? (DSDP, IPOD and ODP cores have disturbed tops so are unusable). Has anyone even checked? Tyrrell (2011) summarized a range of potential oceanographic scenarios but little in the way of data pinpointing diagnostic signatures. Looks like a potential $\mathrm{PhD}$ thesis for someone.

What is the long-term preservation potential of any identifying criteria for the so-called "Anthropocene"? Likely it will be small because most of the studies describing evidence of human alterations occur in geomorphic areas that are dominantly erosional. Few examples have been reported from areas of sediment deposition that have larger preservation potential (See references cited above).

A working limestone quarry operates near my residence. Is the changing vertical cut and quarry floor an "excavation surface"? Is the "excavation surface" in a quarry ten miles away and abandoned 50 years ago coeval? Perhaps the IGC should form a subcommittee to evaluate that surface for its utility in "Anthropocene" sequence stratigraphy.

If the reader is offended by my questions and bemusement, please be advised that the following quote,

"A boundary at this time need not have a Global Boundary Stratotype Section and Point (GSSP or 'golden spike') but can be defined by a Global Standard Stratigraphic Age (GSSA), i.e. a point in time of the human calendar" (Zalasiewicz et al, In Press),

appears to undermine the standards of the revised Stratigraphic Code that has served us well in various forms since the 1930's, although it is not the first time such a variance was made. It also raises substantive questions as to whether geology is well served by "Anthropocene" and whether it has any utility at all. Various isotopes are used to determine rates of surficial, sedimentological, and geomorphic change and a new stratigraphic term really doesn't improve our understanding of the associated processes. Having completed and published research on modern and ancient sediments, "Anthropocene" adds nothing to my findings and interpretations. However, it may make for longer and "snazzier" titles of these publications. Expressed in another way, Desnoyers, Lyell and Gervais, the founders of Quaternary epochs, must be spinning in their graves.

More than sixty years ago the eminent sedimentary petrologist at Penn State University, Paul D. Krynine, defined stratigraphy as "the triumph of nomenclature over common sense." Although "Anthropocene" may have utility as a period of human history, using it in geology and the associated ICS pontifications and scholarly papers prove Krynine to be correct because the term has no geological utility.

\section{Selected References}

Corcoran, P.L., Charles J. Moore and Kelly Jazvac, 2014, An anthropogenic marker horizon in the future record: GSA Today: v. 24, no. 6, doi: 10.1130/ GSAT-G198A.1

Edgeworth, M., Richter, D.B., Waters,C., Haff, P Neal, C and Price, S. J 2015, Diachronous beginnings of the Anthropocene: The lower bounding surface of anthropogenic deposits: The Anthropocene Review: DOI: $10.1177 / 2053019614565394$

Tyrell, T, 2011, Anthrpogenic modifications of the oceans: Phil. Trans. Royal Sc. London, A, DOI: 10.1098/rsta.2010.0334

Zalasiewicz, J., (and 25 others), In Press. When did the Anthropocene begin? A mid-twentieth century boundary level is stratigraphically optimal: Quaternary International, http://dx.doi.org/10.1016/j.quaint.2014.11.045 